\title{
The Effects of Head Cooling on Endurance and Neuroendocrine Responses to Exercise in Warm Conditions
}

\author{
L. ANSLEY ${ }^{1}$, G. MARVIN ${ }^{2}$, A. SHARMA ${ }^{2}$, M. J. KENDALL ${ }^{3}$, D. A. JONES ${ }^{2}$, \\ M. W. BRIDGE ${ }^{2}$
}

${ }^{1}$ School of Psychology and Sport Sciences, Northumbria University, ${ }^{2}$ School of Sport \& Exercise Sciences, University of Birmingham, ${ }^{3}$ Clinical Investigations Unit, Queen Elizabeth Hospital, Birmingham, United Kingdom

Received April 5, 2007

Accepted September 12, 2007

On-line November 30, 2007

\begin{abstract}
Summary
The present study investigated the effects of head cooling during endurance cycling on performance and the serotonergic neuroendocrine response to exercise in the heat. Subjects exercised at $75 \% \mathrm{VO}_{2 \max }$ to volitional fatigue on a cycle ergometer at an ambient temperature of $29 \pm 1.0{ }^{\circ} \mathrm{C}$, with a relative humidity of approximately $50 \%$. Head cooling resulted in a $51 \%(p<0.01)$ improvement in exercise time to fatigue and Borg Scale ratings of perceived exertion were significantly lower throughout the exercise period with cooling $(p<0.01)$. There were no indications of peripheral mechanisms of fatigue either with, or without, head cooling, indicating the importance of central mechanisms. Exercise in the heat caused the release of prolactin in response to the rise in rectal temperature. Head cooling largely abolished the prolactin response while having no effect on rectal temperature. Tympanic temperature and sinus skin temperature were reduced by head cooling and remained low throughout the exercise. It is suggested that there is a coordinated response to exercise involving thermoregulation, neuroendocrine secretion and behavioural adaptations that may originate in the hypothalamus or associated areas of the brain. Our results are consistent with the effects of head cooling being mediated by both direct cooling of the brain and modified cerebral artery blood flow, but an action of peripheral thermoreceptors cannot be excluded.
\end{abstract}

\section{Key words}

Prolactin - Hyperthermia - Head Cooling - Exercise - Central Fatigue

\section{Corresponding author}

L. Ansley, School of Psychology and Sport Sciences, Northumbria University, Newcastle upon Tyne, NE1 8ST, United Kingdom. E-mail: les.ansley@northumbria.ac.uk

\section{Introduction}

Fatigue during sub-maximal endurance exercise is often difficult to attribute to peripheral mechanisms, such as substrate depletion or metabolite accumulation, particularly in the case of fit individuals where the exercise lasts less than $60 \mathrm{~min}$. In such cases the inability to continue exercising may be due to central fatigue mechanisms, whereby a loss of motivation and/or motor cortical activity are the limiting factors (Davis 1995b). The precise mechanism of the central fatigue process is unknown although there has been particular interest in the role of central serotonergic pathways (Davis 1995a, Newsholme and Blomstrand 1995).

Raised body temperature, mediated through central mechanisms, may have a role to play limiting endurance exercise (Bruck and Olschewski 1987) and there are several strands of evidence to support this view. The first is the common observation that endurance times are reduced at high ambient temperatures (Galloway and Maughan 1997). It has been suggested that some aspect of body temperature per se may be the limiting factor (Bruck and Olschewski 1987, Nielsen et al. 1993) and this may be more important than circulatory failure or metabolic depletion that have previously been considered to limit this type of exercise (Fink et al. 1975, Kozlowski et al. 1985).

A second strand of evidence supporting the role of body temperature in mediating central fatigue concerns the release of stress hormones. Prolactin, together with a number of other pituitary hormones, in significant 
concentrations close to the point of fatigue at exercise intensities above about $65 \% \mathrm{VO}_{2} \max$ (Brisson et al. 1981, Luger et al. 1988, Quirion et al. 1990, Luger et al. 1992). A linear relationship has been reported between core temperature and blood prolactin concentration during exercise and heat stress alone is known to mediate prolactin release (Mills and Robertshaw 1981, Christensen et al. 1985). It has been suggested that body (Brisson et al. 1986) or, more specifically, brain (Brisson et al. 1989) temperature is an important factor causing prolactin release during exercise. Head and facial cooling may reduce brain temperature as a result of cool facial blood returning to the brain (Cabanac and Caputa 1979, Cabanac et al. 1987) and this attenuates the prolactin response to exercise in the heat whilst not affecting core temperature (Brisson et al. 1989, Quirion et al. 1990).

Prolactin release is, at least partly under the control of the serotonergic pathways (Van De Kar et al. 1996, Bridge et al. 2003b) and 5-HT agonists such as buspirone stimulate the release of prolactin (Eison and Temple Jr. 1986, Marvin et al. 1997). Stimulation of central 5-HT activity in this way has also been shown to reduce exercise times in man (Wilson and Maughan 1992) whilst potentiating prolactin release (Marvin et al. 1997).

It is evident that there are close associations between the processes of central fatigue and the release of several pituitary hormones, suggesting there may be common underlying neural mechanisms. The purpose of the present study was to explore this possibility. The first objective was to determine whether head cooling has parallel actions on prolactin release, perceived exertion and time to fatigue during submaximal exercise in the heat. Secondly, since it has been shown that tympanic temperature is a valid measure of selective brain cooling (Cabanac 1993), tympanic temperature was measured to see whether there is any evidence that head cooling acts through direct cooling of the hypothalamus.

\section{Methods}

\section{Subjects}

Nine healthy, recreationally active male volunteers gave their consent to participate in the study that was approved by the local Ethics Committee. The mean ( \pm S.D.) age, weight and $\mathrm{VO}_{2} \mathrm{max}$ of the subjects were $24 \pm 7$ years, $81 \pm 7 \mathrm{~kg}$ and $53 \pm 6 \mathrm{ml} \cdot \mathrm{min}^{-1} \cdot \mathrm{kg}^{-1}$, respectively This study complied with the Declaration of Helsinki as adopted at the $52^{\text {nd }}$ WMA General Assembly, Edinburgh, October 2000 (2000).

\section{Experimental procedures}

Exercise was carried out on an electrically braked cycle ergometer (Lode Excalibur, Holland) with pedal rate maintained between 70 and $90 \mathrm{rpm}$. The protocol consisted of 3 visits, each separated by at least seven days:

\section{Visit 1: Maximal oxygen uptake ( $\left.\mathrm{VO}_{2} \max \right)$}

Subjects exercised continuously on the cycle ergometer whilst the workload increased in steps of $30 \mathrm{~W}$ every 2 min until $80 \%$ of the age-predicted maximum heart rate was achieved. Thereafter a discontinuous protocol was used during which subjects were allowed up to $10 \mathrm{~min}$ rest between workload increments, each of which was 3-4 $\mathrm{min}$ in duration. Gas samples were collected during the last 30 seconds of each workload. A workload corresponding to $75 \% \mathrm{VO}_{2} \max$ was identified for each subject.

\section{Visit 2 and 3}

Exercise was performed in a climatic enclosure built from polythene sheeting with 3 electric convection heaters that were adjusted to maintain the ambient temperature at $27-29{ }^{\circ} \mathrm{C}$ and relative humidity at $40-60 \%$, due to the introduction of the water vapour into the ambient air during the cooling trials it was difficult to maintain the relative humidity within a smaller range.

Exercise was performed at the same time of day for each subject. Subjects arrived at the laboratory wearing shorts and a short-sleeved shirt after an overnight fast and rested in a supine position for $15 \mathrm{~min}$. A $20 \mathrm{G}$ cannula (Venflon) was inserted into a superficial forearm vein and kept patent by infusion of $0.9 \%$ saline, $3 \mathrm{ml}$ every $15 \mathrm{~min}$. The subjects rested in a semi-supine position for 1 hour before exercising to volitional fatigue at a workload corresponding to $75 \% \mathrm{VO}_{2} \mathrm{max}$, performed with no cooling (C) or with head cooling (HC). In the HC trial three fans (centre, $45^{\circ}$ left and $45^{\circ}$ right) were placed $50 \mathrm{~cm}$ from the subject's face and positioned facing upwards so as to cool only the head. A fine mist of water was sprayed over the subject's head at 30 second intervals $\left(5-10 \mathrm{ml} \cdot \mathrm{min}^{-1}\right)$. Subjects consumed $500 \mathrm{ml}$ of water one hour before exercise and were encouraged to drink water ad libitum throughout exercise. The order in which the trials were performed was randomised.

\section{Blood collection}

Venous blood samples $(3 \mathrm{ml})$ were obtained immediately before, and at 5-min intervals during, 
exercise and at the point of fatigue. $100 \mu$ of whole blood was immediately added to $1 \mathrm{ml}$ of $0.3 \mathrm{M}$ perchloric acid (PCA) for analysis of blood lactate. Haematocrit was determined in duplicate using capillary tubes and a Hawksley (UK) microcentrifuge. The remaining whole blood was left to clot at room temperature for $20 \mathrm{~min}$ and serum collected for determination of prolactin and glucose concentrations. Samples were stored at $-70{ }^{\circ} \mathrm{C}$ and all assays were performed within 6 weeks.

\section{Blood analysis}

Blood lactate concentrations were measured in the supernatant of the PCA denatured blood using an $\mathrm{NAD}+/ \mathrm{NADH}$ linked enzymatic spectrophotometric assay. Serum prolactin was determined by radioimmunoassay (Chelsea Kits, UK). The inter- and intra- assay coefficients of variation were $2.7 \%$ and $5.9 \%$, respectively, over the appropriate concentration range (71-2160 $\left.\mathrm{mIU}^{-1}{ }^{-1}\right)$. Serum glucose concentrations were determined using a quantitative enzymatic (hexokinase) method (Sigma Diagnostics, Poole, UK).

\section{Gas analysis}

Expired air was collected in Douglas bags during the last 30 seconds of each workload during the $\mathrm{VO}_{2}$ max test and during the $10^{\text {th }}, 20^{\text {th }}$ and $30^{\text {th }}$ min of visits 2 and 3. The air was analysed for percentage oxygen and carbon dioxide composition (Servomex series 1400B, Crowborough, UK) and volume measured with a Harvard dry gas meter (Edenbridge, UK). Oxygen uptake $\left(\mathrm{VO}_{2}\right)$, minute ventilation $\left(\mathrm{V}_{\mathrm{E}}\right)$ and respiratory exchange ratio (RER) were calculated using the Haldane transformation. The fractional utilisation of $\mathrm{VO}_{2}$ and $\mathrm{V}_{\mathrm{E}}$ during the $\mathrm{HC}$ and $\mathrm{C}$ trials was calculated as the percentage of the peak values attained in the maximal test.

\section{Temperature measurement}

Ambient temperature during exercise was measured using a dry bulb mercury thermometer and relative humidity calculated from the dry and wet bulb thermometer differential. Rectal temperature $\left(\mathrm{T}_{\text {rec }}\right)$ was measured using a thermistor probe inserted $10-12 \mathrm{~cm}$ into the rectal ampulla, connected to a Wheatstone bridge and voltmeter. The system was calibrated against an electronic thermometer over a range of $30-50{ }^{\circ} \mathrm{C}$. Tympanic temperature $\left(\mathrm{T}_{\text {tymp }}\right)$ and skin temperature around the nasal sinus region $\left(\mathrm{T}_{\text {skin }}\right)$ were measured using an infrared thermometer (First Temp, Genius, UK). The tympanic membrane was kept dry throughout the exercise period by inserting a small dry cotton wool bud into the ear after each measurement. All temperatures were recorded before exercise, and then at 5-min intervals up to and including the time of fatigue.

\section{Perceived exertion and heart rate}

Ratings of perceived exertion (RPE) were recorded every $5 \mathrm{~min}$ during exercise using a 6 to 20 point scale (Borg 1970). Heart rate was measured by telemetry (Sportstester PE 3000, Polar OY, Finland) and recorded every $5 \mathrm{~min}$ during exercise and at the time of fatigue.

\section{Data and statistical analysis}

Data are reported as mean and standard error mean, unless otherwise stated, and significance was determined using a two way repeated measures analysis of variance (ANOVA) and Student's t-test, where appropriate. Because the times to fatigue were different in the two experimental conditions, several comparisons were made. The majority of subjects managed at least 20 min of exercise in both conditions so up to this time it was possible to compare equivalent time points in the two trials. Secondly, the values at fatigue in the control trial $\left(\mathrm{C}_{\text {fatigue }}\right)$ were compared with the values at the same time point in the $\mathrm{HC}$ trial. Finally, comparisons were made between final values at $\mathrm{C}_{\text {fatigue }}$ and $\mathrm{HC}_{\text {fatigue. }}$ For the purposes of ANOVA, paired data at equivalent time points up to $20 \mathrm{~min}$ and at time $\mathrm{C}_{\text {fatigue }}$ were used. Location of differences was determined by the Tukey test. Where data were found not to be normally distributed (exercise time to fatigue), they are reported as median and inter-quartile range (IQ range) and significance was determined by a Wilcoxon matched pairs signed ranked test.

\section{Results}

Exercise time and rating of perceived exertion (Fig. 1 and Fig. 2)

All the subjects reported that exercise with head cooling was more comfortable than under the control conditions. The greater subjective ease of the exercise was reflected in the Borg scale ratings, which were significantly lower at all times during the exercise with head cooling $(p<0.001)$. Eight of the nine subjects were able to exercise for longer with head cooling and the one who did not show this pattern subsequently reported feeling slightly unwell during the week of his head 


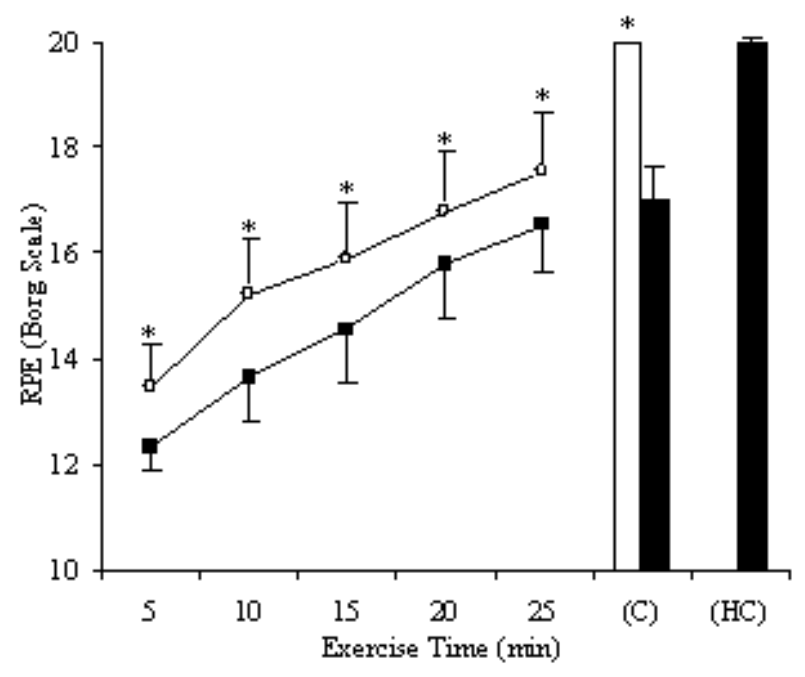

Fig. 1. Ratings of perceived exertion during exercise (Borg, 1971). - head cooling trial, $O$ control trial; (C) - fatigue time point in the control trial, $(\mathrm{HC})$ - fatigue in the head cooling trial. Significant differences were found at equivalent time points from 5 min up the point of fatigue in the control trial $\left(\mathrm{C}_{\text {fatigue }}\right)$. Data are mean \pm S.E.M. $* P<0.05$.

cooling trial although his results have still been included in the analysis.

On average, head cooling resulted in a $51 \%(21$ $65 \%$, IQ range, $\mathrm{p}<0.02$ ) improvement in the median exercise time to fatigue, $45 \mathrm{~min}$ (29-61 $\mathrm{min}$, IQ range) with head cooling compared to $24 \mathrm{~min}$ (22-47 $\mathrm{min}$, IQ range) for the control ride.

\section{Physiological measurements}

Head cooling had no obvious effects on the main physiological response to exercise at equivalent time points. Heart rates were similar at the same time points during the exercise in the two conditions and the point of fatigue (HC $172 \pm 4$ beats. $\min ^{-1}$, C $177 \pm 3$ beats. $\mathrm{min}^{-1}$ ). Blood lactates increased during the initial 10-15 min of exercise to reach a steady state in 7 of the 9 subjects. There were no differences between the two exercise conditions either during the exercise or at the point of fatigue (HC 6.8 $\pm 1.2 \mathrm{mmol}^{-1} \mathrm{l}^{-1}$ C $7.5 \pm 0.6 \mathrm{mmol} . \mathrm{l}^{-1}$ ).

Similarly, there were no significant differences between the two trials in the serum glucose concentrations $(p=0.245)$, which remained constant with no signs of hypoglycaemia during, or at the end of, exercise. Head cooling had no significant effect $(p>0.05)$ on either fractional oxygen uptake $\left(\% \mathrm{VO}_{2} \max : \mathrm{HC}\right.$ $76 \pm 6 \%$, C $77 \pm 6 \%$ ) or fractional minute ventilation (\% $\mathrm{V}_{\mathrm{E}} \mathrm{max}: \mathrm{HC} 57 \pm 14 \%$, C $58 \pm 12 \%$ ). There was an increase in both $\mathrm{VO}_{2}$ and $\mathrm{V}_{\mathrm{E}}$ with time during the exercise but this was similar in the two conditions.

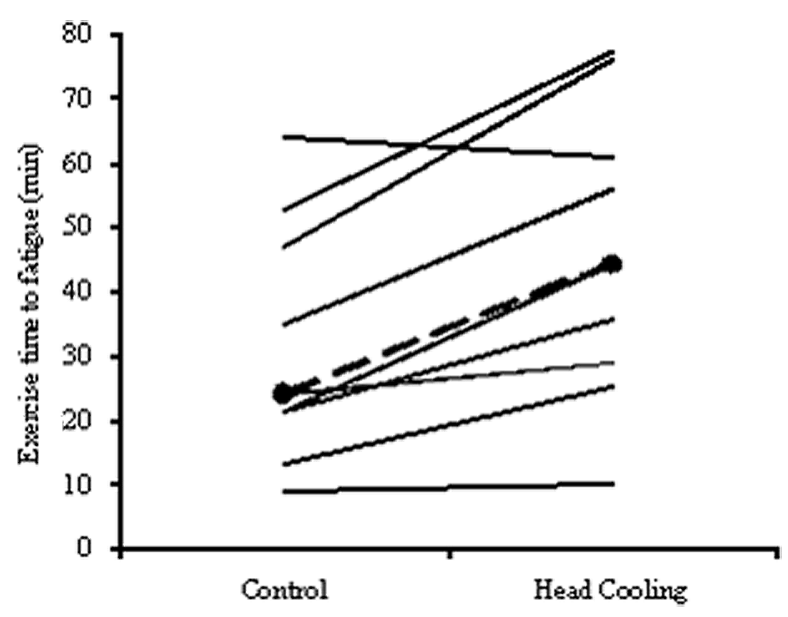

Fig. 2. Completion times for the head cooling trial and the control trial. Mean data are depicted by the broken line.

During the $\mathrm{HC}$ and $\mathrm{C}$ trials seven and eight subjects completed more than $20 \mathrm{~min}$, respectively while six and four subjects continued longer than $30 \mathrm{~min}$, respectively. Haematocrit showed no change during exercise or between trials providing an indication that hydration status was similar in both trials.

\section{Temperature measurements (Fig. 3, Fig. 4 and Fig. 5)}

At rest $\mathrm{T}_{\text {tymp }}$ was significantly lower than $\mathrm{T}_{\text {rec }}$ for both trials. During the control trial both $T_{\text {tymp }}$ and $T_{\text {rec }}$ increased over time and towards the latter stages of the exercise $\mathrm{T}_{\text {tymp }}$ and $\mathrm{T}_{\text {rec }}$ and were very similar.

Head cooling attenuated the response of $\mathrm{T}_{\text {tymp }}$ during the exercise and $\mathrm{T}_{\text {tymp }}$ remained virtually constant throughout the bout. Head cooling had no significant effect on $T_{\text {rec }}$ although there was a tendency for $T_{\text {rec }}$ to be higher in the head cooling condition. $\mathrm{T}_{\text {tymp }}$ was very different at the point of fatigue between the two conditions with the $\mathrm{T}_{\text {tymp }}$ at $\mathrm{HC}_{\text {fatigue }}$ almost $2.5^{\circ} \mathrm{C}$ lower than the $\mathrm{T}_{\text {tymp }}$ at $\mathrm{C}_{\text {fatigue }}$. In contrast, $\mathrm{T}_{\text {rec }}$ at fatigue was similar for both conditions ( $\mathrm{HC} 39.0 \pm 0.6{ }^{\circ} \mathrm{C}, \mathrm{C} 38.9 \pm 0.8^{\circ} \mathrm{C}$ ).

$\mathrm{T}_{\text {skin }}$ at rest was the same for both trials (HC $31.1 \pm 0.5{ }^{\circ} \mathrm{C}, \mathrm{C} 31.3 \pm 0.3{ }^{\circ} \mathrm{C}$ ) but during the head cooling trial $\mathrm{T}_{\text {skin }}$ dropped significantly at $5 \mathrm{~min}$ and continued to remain lower for the duration of the trial $\left(25.6 \pm 0.9{ }^{\circ} \mathrm{C}\right)$, whereas in the control trial $\mathrm{T}_{\text {skin }}$ rose in the initial $15 \mathrm{~min}$ before reaching a plateau $\left(34.8 \pm 0.4{ }^{\circ} \mathrm{C}\right)$.

\section{Prolactin concentration (Fig. 6 and Fig. 7)}

There was a wide variation in the magnitude of the prolactin response to exercise under both conditions. There was no significant difference in the resting values between trials but head cooling significantly and 


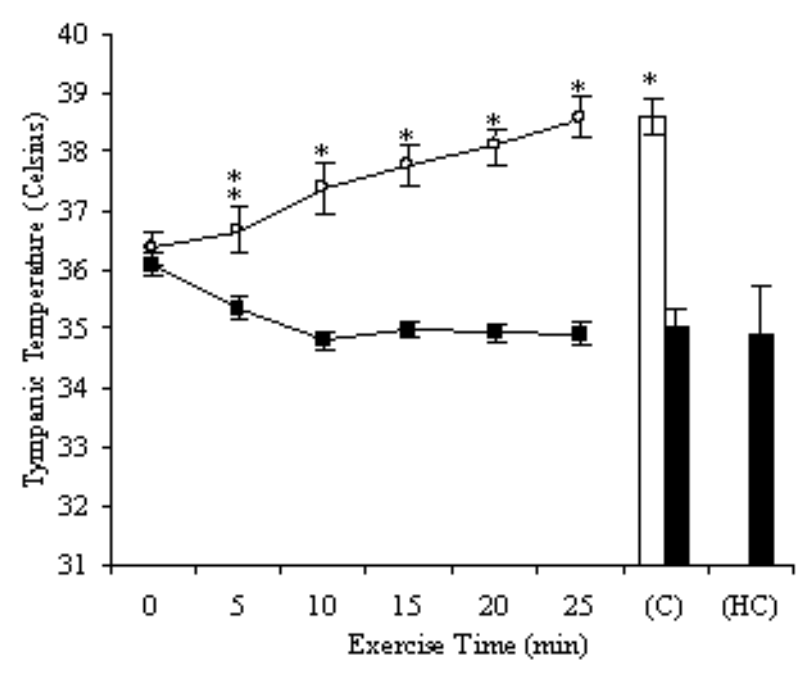

Fig. 3. Tympanic temperature during exercise. head cooling trial, $O$ control trial; $(\mathrm{C})$ - fatigue time point in the control trial, $(\mathrm{HC})$ - fatigue in the head cooling trial. Significant differences were found at equivalent time points from $5 \mathrm{~min}$ up the point of fatigue in the control trial $\left(C_{\text {fatigue }}\right)$. Data are mean \pm S.E.M. $* \mathrm{P}<0.05$.

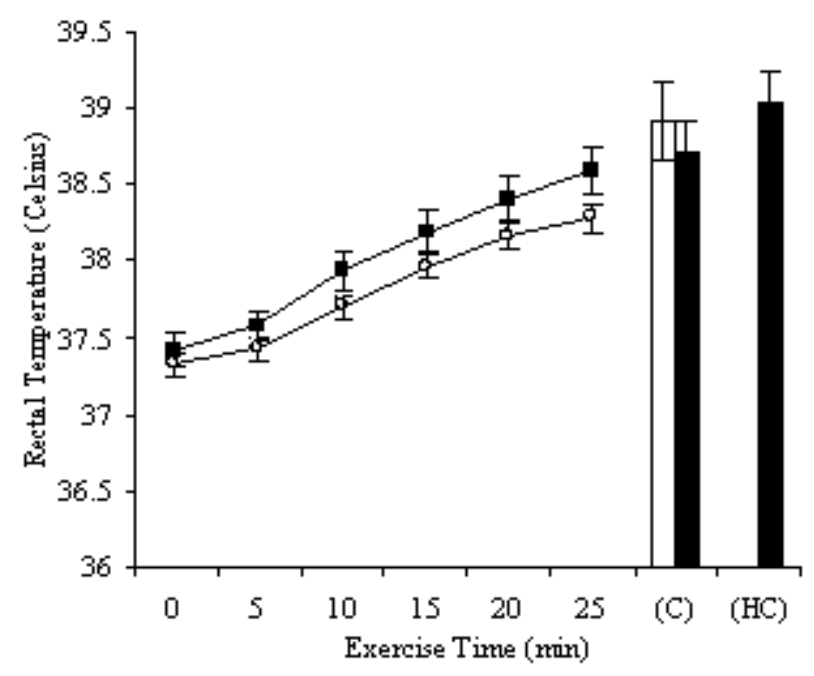

Fig. 4. Rectal temperature during exercise. $\mathbf{a}$ head cooling trial, O control trial; $(\mathrm{C})$ - fatigue time point in the control trial, $(\mathrm{HC})$ fatigue in the head cooling trial. No differences between trials at any equivalent time points were observed. Data are mean \pm S.E.M.

consistently attenuated the prolactin response at all time points from $10 \mathrm{~min}$ into the exercise $(\mathrm{p}=0.011)$.

Serum prolactin concentrations were raised nearly six-fold (range 170-1943\%) of resting values at $\mathrm{C}_{\text {fatigue }}$ under control conditions compared to a two-fold increase (range 106-505\%) at the same time point in HC. At $\mathrm{HC}_{\text {fatigue }}$ the prolactin was elevated approximately three fold (range 151-982\%), which was still considerably less than the increase at $\mathrm{C}_{\text {fatigue }}$ in the control trial.

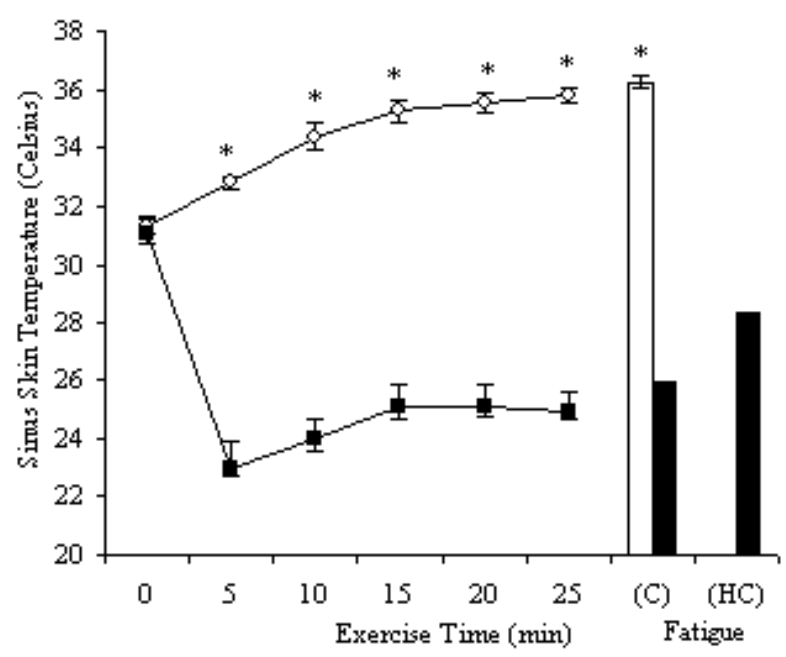

Fig. 5. Sinus skin temperature during exercise. a head cooling trial, $O$ control trial; $(\mathrm{C})$ - fatigue time point in the control trial, (HC) - fatigue in the head cooling trial. No differences between trials at any equivalent time points were observed. Data are mean \pm S.E.M. $* P<0.05$.

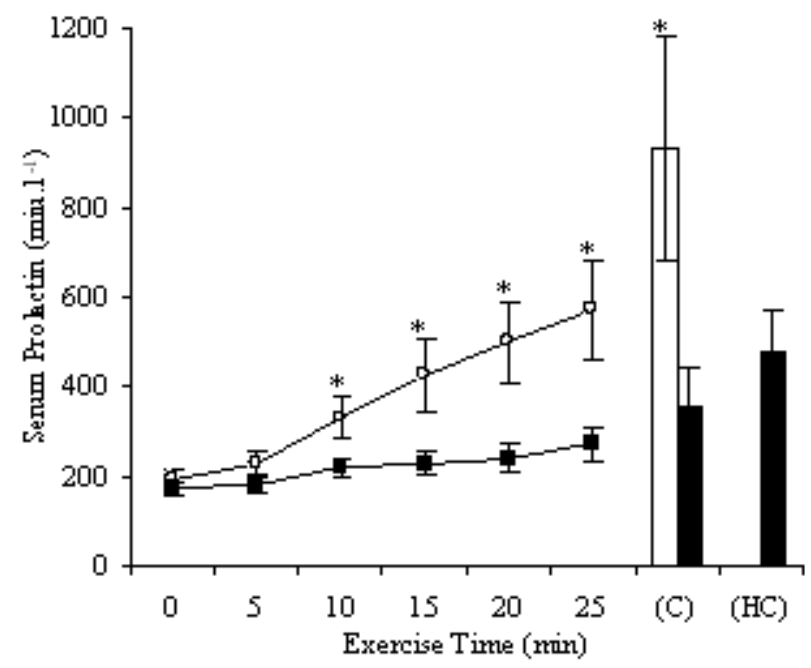

Fig. 6. Serum prolactin response to exercise. $\mathbf{m}$ head cooling trial, $O$ control trial; $(C)$ - fatigue time point in the control trial, $(\mathrm{HC})$ - fatigue in the head cooling trial. Significant differences were found at equivalent time points from $10 \mathrm{~min}$ up the point of fatigue in the control trial $\left(\mathrm{C}_{\text {fatigue }}\right)$. Data are mean \pm S.E.M. $* P<0.05$.

\section{Discussion}

The present study has demonstrated that head cooling leads to a considerable improvement in whole body sub-maximal exercise performance in a warm environment. Therefore even accounting for the potential variability inherent in time-to-exhaustion trials (3-30 \%) (McLellan et al. 1995) the exercise duration is still significantly longer with head cooling. The effect is most 


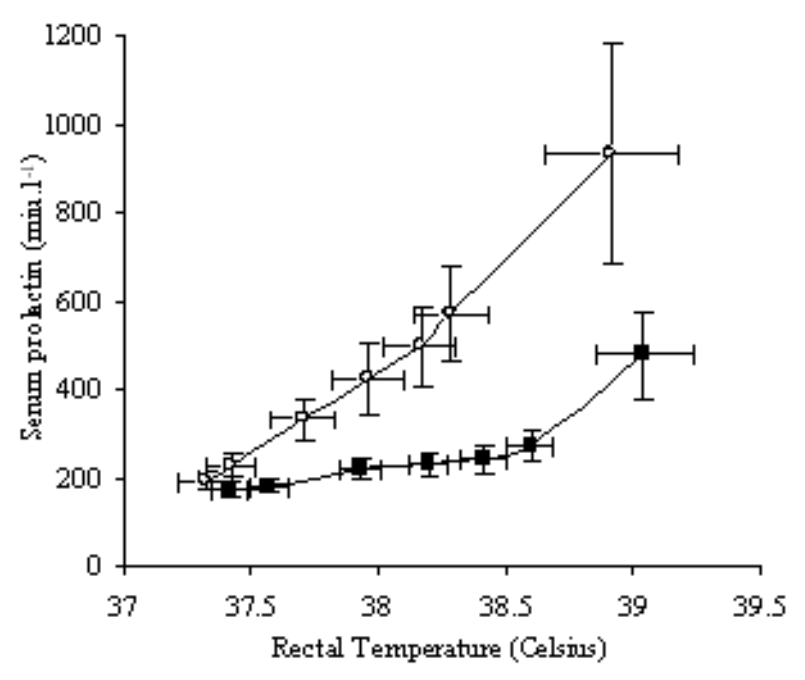

Fig. 7. Rectal temperature - serum prolactin relationship during exercise. head cooling trial, $O$ control trial. Data are mean \pm S.E.M.

probably associated with a reduction in central fatigue and changes in prolactin release are consistent with the hypothalamus or associated areas being involved in the process. The results suggest there is a potential association between thermoreceptors, the release of stress hormones and central fatigue mechanisms. Although numerous studies have looked at the effect of ambient temperature on endurance exercise performance (Gonzalez-Alonso et al. 1999) and head and/or face cooling has been shown to improve performance of repeated handgrip exercise in the heat (Hirata et al. 1987) we believe the present study is the first to report the effects of head cooling on whole body sub-maximal endurance performance.

Exercise studies, such as these, cannot be conducted in a double blind fashion so it is important to consider whether the improvements in performance, which were dramatic in some cases, were the result of experimental bias. The subjects exercising in the heat might have "just given up" or the investigators could have been especially encouraging to the subjects with head cooling but these considerations are unlikely to have had much impact on the results. All the subjects were experienced in this type of exercise and there was a strong competitive ethos with all aspects of the testing. The treatment order was randomised and consequently it is unlikely that the improvement in performance with cooling was due to a learning effect. Subjects were not informed of either the exercise time or how they were performing compared to the previous trial. The main argument against the improvements being an artefact comes however from the prolactin measurements since these provide an objective index of the stress of the exercise test. Had subjects exercising in the heat "given up" it is unlikely that their prolactin levels would have reached higher values than seen after a longer period of exercise with head cooling (Fig. 6).

There are a number of mechanisms, both central and peripheral, that might account for the difference in exercise performance seen with and without head cooling. However, there were no indications in the present study that differences in exercise time between control and head cooling conditions were the result of peripheral fatigue. Circulating lactate levels were the same in both protocols and subjects reached steady plateau values by about $15 \mathrm{~min}$ into the exercise. There was no evidence of a rapid rise in lactate at the point of fatigue that would suggest a metabolic crisis nor was there any hyperventilation or change in RER. Ventilation and heart rates, although high, were very similar in both experimental situations and did not reach the values observed at fatigue in the incremental maximal test. It is notable that in the present experiments rectal temperatures were the same in the two situations showing that the muscle and visceral organs were working under similar conditions.

Face cooling during passive hyperthermia (LeBlanc et al. 1976, Cabanac and Caputa 1979), submaximal (Riggs Jr. et al. 1983, Brisson et al. 1989) and maximal exercise (Endo et al. 2003) is well known to result in a bradycardia attributed to a vagal reflex from cold stimulated skin receptors. Borg ratings of perceived exertion are closely linked to heart rate and so an induced bradycardia might lead to a reduction in perceived exertion. However, in the present study, head cooling did not produce a bradycardia during exercise probably because at exercise intensities above about $65 \% \mathrm{VO}_{2 \max }$ the exercise-induced drive for heart rate overwhelms any reflex activity (Quirion et al. 1990).

The lack of any evidence for peripheral failure, together with the lower ratings of perceived exertion with head cooling, suggest that the improvements in exercise tolerance are likely to be due to central rather than peripheral mechanisms. This conclusion is in agreement with other researchers (Bruck and Olschewski 1987, Nielsen et al. 1993, Pitsiladis et al. 2002) who have suggested that loss of motivational drive is a critical factor limiting exercise tolerance in the heat.

Exercise under control conditions resulted in a 
steady increase in $\mathrm{T}_{\text {tymp }}$ that mirrored the rise in $\mathrm{T}_{\text {rec }}$ and was associated with increases in serum prolactin. Prolactin release has been shown to be directly proportional to $\mathrm{T}_{\text {rec }}$ (Mills and Robertshaw 1981, Christensen et al. 1985) and this was broadly true of the results of this study although the relationship was curvilinear rather than linear (Fig. 7). Head cooling modified this relationship and virtually abolished the prolactin response to exercise demonstrating that head cooling has a major influence on hypothalamic function.

An improvement in perception of effort and thermal comfort and an attenuation in the PRL response are common findings in studies that have looked at face cooling during physical work in hot conditions (Sato et al. 1996, Armada-da-Silva et al. 2004, Mundel et al. 2006, Mundel et al. 2007). In this study, the fact that perceived exertion, the onset of fatigue and secretion of prolactin were all affected in a similar way by head cooling indicates that there are common neural pathways responsible for integrating the body's response to exercise in the heat. This is a three-fold response consisting of thermoregulation, the secretion of stress hormones and behavioural adaptations leading to a disinclination to exercise. This latter response may be likened to the behavioural responses of many animals to hyperthermia, namely a reduction in motor activity and a search for a cooler environment. Temperature regulation and secretion of prolactin are controlled in the preoptic area and hypothalamus and finding that these are related to perceptions of exertion suggests that behavioural changes may also originate, or be heavily influenced by, the activity of these areas.

Given that head cooling had a profound effect on exercise, the question arises as to how the effect is mediated. Head cooling resulted in a large reduction of $\mathrm{T}_{\text {tymp }}$ and the method used was adapted from that of Cabanac et al. (1987) who argue that a reduction of $\mathrm{T}_{\text {tymp }}$ is evidence of selective brain cooling. Others, however others have opposed this view (Brengelmann 1993, Nielsen and Jessen 1992, Simon 2007). The question to be answered with regard to the present work is whether the tympanic temperature we have measured is a reliable indicator of hypothalamic temperature. Certainly the infrared method we have used has been validated in a number of studies (Jakobsson et al. 1992, Smith and Fehling 1996), which assures us that our method was reliable. However, there has been much debate over the validity of using $\mathrm{T}_{\text {tymp }}$ as a measure of hypothalamic temperature (Cabanac 1993, Brengelmann 1993). Indeed, recently Simon (2007) presented a strong argument that $\mathrm{T}_{\text {tymp }}$ cannot be used as a consistent index of brain temperature. Despite this, our observations are in accord with the conclusion that face cooling is the main mediator of prolactin release (Mundel et al. 2006) possibly through the mechanism of selectively cooling the brain (Brisson et al. 1991) although, it has to be noted that the reduction in $\mathrm{T}_{\text {tymp }}$ was large $\left(2.5^{\circ} \mathrm{C}\right)$ and very similar to that of nearby skin. This raises the possibility, first, that the tympanic temperature we measured may have been contaminated to some degree by the skin temperature and, secondly, that peripheral thermoreceptors may have had some role to play. We have shown that simply exercising in a cool environment $\left(15^{\circ} \mathrm{C}\right)$ has a similar effect to specific head cooling in reducing the prolactin response to exercise and this was attributed to the effect of lower mean skin temperature (Bridge et al. 2003a). Furthermore it appears that changes in skin temperature independent of core temperature can contribute to the regulation of $\mathrm{PRL}$ release during exercise in the heat (Low et al. 2005). Armada-da-Silva et al. (2004) postulate that cooling of the face may minimise reduction in blood flow in the cerebral artery that has previously been associated with hyperthermia (Nybo and Nielsen 2001a). These changes in cerebral circulation have been shown to be strongly related to perceptual effort (Nybo et al. 2002). Furthermore, Nybo and Nielsen (2001b) have demonstrated in several studies that the sensations of fatigue associated with hyperthermia are derived from the brain and not from a failure in the peripheral contractile mechanism.

The results presented here indicate that head cooling has a major impact on exercise performance in the heat, modifying the neuroendocrine response, perceived exertion and the time to fatigue. It is suggested that there is a co-ordinated response to exercise involving thermoregulation, neuroendocrine secretion and behavioural adaptations that may originate in the hypothalamus or associated areas of the brain (Mundel et al. 2007). As to the mechanism by which head cooling achieves these effects, our results are consistent with both a direct cooling of the central thermoreceptors in the preoptic area and modification of cerebral artery blood flow. However, we are aware of the possible role of peripheral thermoreceptors and the interaction of central and peripheral thermoreceptors in the control of the neuroendocrine and behavioural responses to exercise in the heat remain to be elucidated. 


\section{Conflict of Interest}

There is no conflict of interest.

\section{Acknowledgements}

We are grateful for the support of the CFS Research Foundation.

\section{References}

ARMADA-DA-SILVA PAS, WOODS J, JONES DA: The effect of passive heating and face cooling on perceived exertion during exercise in the heat. Eur J Appl Physiol 91: 563-571, 2004.

BORG G: Physical training. 3. Perceived exertion in physical work. Lakartidningen 67: 4548-4557, 1970.

BRENGELMANN GL: Specialized brain cooling in humans? FASEB J 7: 1148-1152, 1993.

BRIDGE MW, WELLER AS, RAYSON M, JONES DA: Ambient temperature and the pituitary hormone responses to exercise in humans. Exp Physiol 88: 627-635, 2003a.

BRIDGE MW, WELLER AS, RAYSON M, JONES DA: Responses to exercise in the heat related to measures of hypothalamic serotonergic and dopaminergic function. Eur J Appl Physiol 89: 451-459, 2003 b.

BRISSON GR, AUDET A, LEDOUX M, MATTON P, PELLERIN-MASSICOTTE J, PERONNET F: Exerciseinduced blood prolactin variations in trained adult males: a thermic stress more than an osmotic stress. Horm Res 23: 200-206, 1986.

BRISSON GR, BOISVERT P, PERONNET F, QUIRION A, SENECAL L: Face cooling-induced reduction of plasma prolactin response to exercise as part of an integrated response to thermal stress. Eur J Appl Physiol Occup Physiol 58: 816-820, 1989.

BRISSON GR, LEDOUX M, PERONNET F, DULAC S, DECARUFEL D, VOLLE MA, RAINVILLE J, AUDET A: Prolactinemia in exercising male athletes. Horm Res 15: 218-223, 1981.

BRISSON GR, PERONNET F, PERRAULT H, BOISVERT P, MASSICOTTE D, GAREAU R: Prolactinotrophic effect of endogenous and exogenous heat loads in human male adults. J Appl Physiol 70: 1351-1355, 1991.

BRUCK K, OLSCHEWSKI H: Body temperature related factors diminishing the drive to exercise. Can J Physiol Pharmacol 65: 1274-1280, 1987.

CABANAC M: Selective brain cooling in humans: "fancy" or fact? FASEB J 7: 1143-1146, 1993.

CABANAC M, CAPUTA M: Natural selective cooling of the human brain: evidence of its occurrence and magnitude. $J$ PhysiolLond 286: 255-264, 1979.

CABANAC M, GERMAIN M, BRINNEL H: Tympanic temperatures during hemiface cooling. Eur J Appl Physiol Occup Physiol 56: 534-539, 1987.

CHRISTENSEN SE, JORGENSEN O, MOLLER J, MOLLER N, ORSKOV H: Body temperature elevation, exercise and serum prolactin concentrations. Acta Endocrinol (Copenh) 109: 458-462, 1985.

DAVIS JM: Carbohydrates, branched-chain amino acids, and endurance: the central fatigue hypothesis. Int J Sport Nutr 5 (Suppl): S29-S38, 1995a.

DAVIS JM: Central and peripheral factors in fatigue. J Sports Sci 13: S49-S53, 1995b.

EISON AS, TEMPLE DL, Jr.: Buspirone: review of its pharmacology and current perspectives on its mechanism of action. Am J Med 80: 1-9, 1986.

ENDO M, TAUCHI S, HAYASHI N, KOGA S, ROSSITER HB, FUKUBA Y: Facial cooling-induced bradycardia does not slow pulmonary VO2 kinetics at the onset of high-intensity exercise. J Appl Physiol 95: 1623-1631, 2003.

FINK WJ, COSTILL DL, VAN HANDEL PJ: Leg muscle metabolism during exercise in the heat and cold. Eur J Appl Physiol Occup Physiol 34: 183-190, 1975.

GALLOWAY SD, MAUGHAN RJ: Effects of ambient temperature on the capacity to perform prolonged cycle exercise in man. Med Sci Sports Exerc 29: 1240-1249, 1997.

GONZALEZ-ALONSO J, TELLER C, ANDERSEN SL, JENSEN FB, HYLDIG T, NIELSEN B: Influence of body temperature on the development of fatigue during prolonged exercise in the heat. J Appl Physiol 86: 10321039, 1999. 
HIRATA K, NAGASAKA T, NUNOMURA T, HIRAI A, HIRASHITA M: Effects of facial fanning on local exercise performance and thermoregulatory responses during hyperthermia. Eur J Appl Physiol Occup Physiol 56: 4348, 1987.

JAKOBSSON J, NILSSON A, CARLSSON L: Core temperature measured in the auricular canal: comparison between four different tympanic thermometers. Acta Anaesthesiol Scand 36: 819-824, 1992.

KOZLOWSKI S, BRZEZINSKA Z, KRUK B, KACIUBA-USCILKO H, GREENLEAF JE, NAZAR K: Exercise hyperthermia as a factor limiting physical performance: temperature effect on muscle metabolism. $J$ Appl Physiol 59: 766-773, 1985.

LEBLANC J, BLAIS B, BARABE B, COTE J: Effects of temperature and wind on facial temperature, heart rate, and sensation. J Appl Physiol 40: 127-131, 1976.

LOW D, CABLE T, PURVIS A: Exercise thermoregulation and hyperprolactinaemia. Ergonomics 48: 1547-1557, 2005.

LUGER A, DEUSTER PA, GOLD PW, LORIAUX DL, CHROUSOS GP: Hormonal responses to the stress of exercise. Adv Exp Med Biol 245: 273-280, 1988.

LUGER A, WATSCHINGER B, DEUSTER P, SVOBODA T, CLODI M, CHROUSOS GP: Plasma growth hormone and prolactin responses to graded levels of acute exercise and to a lactate infusion. Neuroendocrinology $\mathbf{5 6}$ : 112-117, 1992.

MARVIN G, SHARMA A, ASTON W, FIELD C, KENDALL MJ, JONES DA: The effects of buspirone on perceived exertion and time to fatigue in man. Exp Physiol 82: 1057-1060, 1997.

MCLELLAN TM, CHEUNG SS, JACOBS I: Variability of time to exhaustion during submaximal exercise. Can J Appl Physiol 20: 39-51, 1995.

MILLS DE, ROBERTSHAW D: Response of plasma prolactin to changes in ambient temperature and humidity in man. J Clin Endocrinol Metab 52: 279-283, 1981.

MUNDEL T, HOOPER PL, BUNN SJ, JONES DA: The effects of face cooling on the prolactin response and subjective comfort during moderate passive heating in humans. Exp Physiol 91: 1007-1014, 2006.

MUNDEL T, BUNN SJ, HOOPER PL, JONES DA: The effects of face cooling during hyperthermic exercise in man: evidence for an integrated thermal, neuroendocrine and behavioural response. Exp Physiol 92: 187-195, 2007.

NEWSHOLME EA, BLOMSTRAND E: Tryptophan, 5-hydroxytryptamine and a possible explanation for central fatigue. Adv Exp Med Biol 384: 315-320, 1995.

NIELSEN B, JESSEN C: Evidence against brain stem cooling by face fanning in severely hyperthermic humans. Pflugers Arch 422: 168-172, 1992.

NIELSEN B, HALES JR, STRANGE S, CHRISTENSEN NJ, WARBERG J, SALTIN B: Human circulatory and thermoregulatory adaptations with heat acclimation and exercise in a hot, dry environment. $J$ Physiol Lond 460: 467-485, 1993.

NYBO L, NIELSEN B: Middle cerebral artery blood velocity is reduced with hyperthermia during prolonged exercise in humans. J Physiol Lond 534: 279-286, 2001a.

NYBO L, NIELSEN B: Perceived exertion is associated with an altered brain activity during exercise with progressive hyperthermia. J Appl Physiol 91: 2017-2023, 2001 b.

NYBO L, MOLLER K, VOLIANITIS S, NIELSEN B, SECHER NH: Effects of hyperthermia on cerebral blood flow and metabolism during prolonged exercise in humans. J Appl Physiol 93: 58-64, 2002.

PITSILADIS YP, STRACHAN AT, DAVIDSON I, MAUGHAN RJ: Hyperprolactinaemia during prolonged exercise in the heat: evidence for a centrally mediated component of fatigue in trained cyclists. Exp Physiol 87: 215$226,2002$.

QUIRION A, BOISVERT P, BRISSON GR, DECARUFEL D, LAURENCELLE L, DULAC S, VOGELAERE P, THERMINARIAS A: Physiological adjustments of facial cooling during exercise. J Sports Med Phys Fitness 30: 264-267, 1990.

RIGGS CE Jr, JOHNSON DJ, KILGOUR RD, KONOPKA BJ: Metabolic effects of facial cooling in exercise. Aviat Space Environ Med 54: 22-26, 1983.

SATO KT, KANE NL, SOOS G, GISOLFI CV, KONDO N, SATO K: Reexamination of tympanic membrane temperature as a core temperature. J Appl Physiol 80: 1233-1239, 1996. 
SIMON E: Tympanic temperature is not suited to indicate selective brain cooling in humans: a re-evaluation of the thermophysiological basics. Eur J Appl Physiol 101: 19-30, 2007.

SMITH DL, FEHLING PC: Reliability of infra-red tympanic thermometry (ITT). Aviat Space Environ Med 67: 272274, 1996.

VAN DE KAR LD, RITTENHOUSE PA, LI Q, LEVY AD: Serotonergic regulation of renin and prolactin secretion. Behav Brain Res 73: 203-208, 1996.

WILSON WM, MAUGHAN RJ: Evidence for a possible role of 5-hydroxytryptamine in the genesis of fatigue in man: administration of paroxetine, a 5-HT re-uptake inhibitor, reduces the capacity to perform prolonged exercise. Exp Physiol 77: 921-924, 1992. 